\title{
Surveilans Infeksi Nosokomial di RSJ Dr. Radjiman Wediodiningrat Lawang, Aplikasi Kriteria McGeer
}

\section{Nosocomial Infection Surveillance at Dr. Radjiman Wediodiningrat Mental Hospital Lawang, McGeer Criteria Application}

\author{
Imelda Fitria D, Lukman Hakim, Tatong Hariyanto \\ Program Studi Magister Manajemen Rumah Sakit Fakultas Kedokteran Universitas Brawijaya Malang
}

\begin{abstract}
ABSTRAK
Infeksi nosokomial merupakan salah satu tolok ukur mutu sebuah rumah sakit yang dipengaruhi karakteristik rumah sakit. Fasilitas kesehatan jangka panjang yang termasuk rumah sakit jiwa, berbeda dari rumah sakit pada umumnya dilihat dari karakteristik penghuninya yang membutuhkan supervisi 24 jam oleh tenaga kesehatan. McGeer mengembangkan sebuah kriteria infeksi nosokomial khusus untuk fasilitas kesehatan jangka panjang karena di fasilitas tersebut minim tindakan invasif. Tujuan penelitian ini adalah untuk mengetahui gambaran infeksi nosokomial di di Rumah Sakit Jiwa Dr. Radjiman Wediodiningrat Lawang (RSJRW) dengan modifikasi kriteria McGeer, dan faktor-faktor yang mempengaruhi kejadian infeksi nosokomial tersebut. Penelitian ini dilakukan di RSJRW pada bulan Februari-April 2016 dengan pasien rawat inap periode bulan April 2016 sebagai populasi. Instrumen dalam penelitian ini menggunakan pedoman baru dan lembar observasi suveilan yang menggabungkan kriteria Kemenkes RI dan kriteria McGeer untuk infeksi nosokomial di fasilitas kesehatan jangka panjang. Tujuan penelitian ini adalah untuk membuktikan adanya kejadian infeksi nosokomial dengan menggunakan Kriteria McGeer, dan sebagai studi pendahuluan surveilans infeksi nosokomial di RSJRW dengan menggunakan Kriteria McGeer. Desain penelitian adalah kuantitatif analitik dengan pendekatan cross sectional. Analisis data menggunakan uji chi-square. Hasil menunjukkan bahwa penggunaan kriteria baru sebagai pedoman surveilans di RSJRWdapat mengidentifikasi 30 insiden infeksi nosokomial tunggal, dengan rate tertinggi infeksi saluran kemih $(20,83 \%$ ) dan plebitis $(11,8 \%$ o). Faktor-faktor yang secara signifikan berpengaruh adalah usia, mobilitas terganggu, pemakaian kateter, pemakaian infus, dan ruangan dengan tindakan invasif lebih berisiko daripada ruangan perawatan lainnya.
\end{abstract}

Kata Kunci: Infeksi nosokomial, kriteria McGeer, RSJ Dr. Radjiman Wediodiningrat Lawang

\begin{abstract}
Nosocomial infection is one of a quality indicator at a hospital which is influenced by hospitals service characteristics. Long-term care facilities which including mental hospital has different specification from general hospital. It can be seen from the resident's characteristic whose needs 24 hours supervision from the healthcare providers. McGeer develop nosocomial infection criteria for long-term care facilities. From 29 wards exist at Dr.Radjiman Wediodiningrat Mental Hospital, only 3 of them providing invasive procedure. The aim of this research is to describe the nosocomial infection surveillance using McGeer Criteria at Dr. Radjiman Wediodiningrat Mental Hospital, and what are the risk factor influencing the nosocomial infections. This research took place at Dr.Radjiman Wediodiningrat Mental Hospital from February-April 2016. The population is as amount of April 2016 inpatients. Instruments in this research using new guidance and surveillance form combining the Kemenkes RI and McGeer's criteria for nosocomial infection in longterm care facilities. Research design is analytic quantitative with cross-sectional approach. The correlations among risk factors to nosocomial infections were analyzed with chi-square. Result shows that using new criteria in surveillance we identify 30 nosocomial incidents, with urinarytract infection $(20,8 \%$ ) and phlebitis $(11,8 \%$ ) as the highest incidence rate. The risk factors that significantly correlated with nosocomial infections are age, impaired mobility, use of catether, use of intravenous line, and invasive-procedure providing wards is more at risk to provide nosocomial infection than other wards.
\end{abstract}

Keywords: Dr. Radjiman Wediodiningrat Mental Hospital, McGeer criteria, nosocomial infection

Korespondensi: Imelda Fitria D. Program Studi Magister Manajemen Rumah Sakit Fakultas Kedokteran Universitas Brawijaya Malang, Jl. Veteran, Malang 65145 Tel. (0341)569117Email: imelda.donosepoetro@gmail.com

DOI: http://dx.doi.org/10.21776/ub.jkb.2017.029.04.12 


\section{PENDAHULUAN}

Infeksi nosokomial merupakan salah satu tolok ukur mutu rumah sakit. World Health Organization menyebutkan, infeksi nosokomial adalah adverse effect (efek yang tidak diinginkan) yang paling sering terjadi di pelayanan kesehatan di seluruh dunia. Ratusan juta pasien mengalami kejadian infeksi nosokomial kesehatan setiap tahunnya, yang mengarah kepada morbiditas, mortalitas, dan kerugian finansial di bidang kesehatan (1). Penelitian WHO pada tahun 2012 menyebutkan, dari setiap 100 pasien rawat inap, di negara maju 7 diantaranya, dan di negara berkembang 10 diantaranya mengalami infeksi nosokomial. Prevalensi infeksi nosokomial di negara berkembang bervariasi diantara 5,7\% sampai dengan $19,1 \%$ (2). Dalam beberapa penelitian disebutkan bahwa kejadian infeksi nosokomial di rumah sakit masih di atas $12 \%(3,4)$.

Setiap fasilitas kesehatan mempunyai perbedaan jenis perawatan, ukuran sebuah fasilitas tersebut, dan akses dokter untuk mendiagnosis, sehingga memerlukan standar yang berbeda (5). Lee memaparkan dalam penelitiannya bahwa karakteristik rumah sakit merupakan faktor terbesar yang mempengaruhi lama hari perawatannya. Rumah sakit jiwa merupakan salah satu bentuk fasilitas kesehatan jangka panjang yang memiliki hari perawatan yang lebih panjang karena berhubungan dengan pola terapi dan stabilisasi pasien sehingga memiliki risiko dan jenis infeksi yang berbeda pula (6).

Burns et al, (5) dan McGeer et al, (7) menyebutkan, panduan dan standar diagnosa infeksi nosokomial di pelayanan kesehatan pada umumnya tidak sesuai dengan fasilitas kesehatan jangka panjang. Sebuah penelitian menyebutkan, di Amerika Serikat kejadian infeksi nosokomial di fasilitas kesehatan jangka panjang mencapai 1,6 juta sampai 3,8 juta kejadian infeksi setiap tahunnya (8). Oleh karena itu McGeer mengembangkan kriteria surveilans infeksi nosokomial yang dirancang untuk fasilitas kesehatan jangka panjang. Meskipun sudah banyak digunakan, di Indonesia masih menggunakan satu kriteria sama yang dikeluarkan oleh Kementrian Kesehatan. Jumlah dan jenis infeksi yang diidentifikasi dengan kriteria McGeer lebih banyak dibandingkan kriteria Kemenkes serta memiliki pola yang berbeda (7).

Eilers menyebutkan terdapat beberapa faktor risiko yang mempengaruhi infeksi nosokomial di fasilitas kesehatan jangka panjang. Penelitian Eilers juga menggunakan Kriteria McGeer sebagai pedomannya. Faktor-faktor tersebut antara lain jenis kelamin, usia, menggunakan kateter urin, menggunakan intravenous line, terdapat luka tekan, terdapat luka lain, disorientasi, inkontinensia, menggunakan kursi roda/bedrest, menjalani operasi maksimal 30 hari sebelumnya, dan dirawat di rumah sakit dalam kurun waktu 3 bulan sebelumnya (9). Pada penelitian terdahulu, Donosepoetro et al, menyebutkan di RSJ Dr. Radjiman Wediodiningrat Lawang masih terdapat kendala pelaporan surveilans yang dapat disebabkan kekhususan kriteria infeksi (10).

Tujuan penelitian ini adalah untuk menggambarkan kejadian infeksi nosokomial di RSJRW apabila menggunakan kriteria McGeer dan mengidentifikasi faktor risiko. Penelitian ini membatasi variabel faktor risiko yang dicari meliputi usia, jenis kelamin, pendidikan, penggunaan kateter urin, penggunaan infus, mobilitas terganggu, ruangan perawatan, dan lama hari perawatan.

\section{METODE}

Penelitian dilakukan dengan pendekatan survei crosssectional. Populasi dalam penelitian ini adalah pasien rawat inap di RSJRW selama bulan April 2016 karena sosialisai penggunaan instrumen McGeer baru dilakukan pada Bulan Maret 2016. Instrumen survei menggunakan penggabungan kriteria McGeer dan Kemenkes untuk surveilans meliputi 12 kriteria infeksi nosokomial; plebitis, ISK, dekubitus, influenza, selulitis, skabies, infeksi jamur, infeksi herpes, kutu rambut, konjungtivitis, gastroenteritis, infeksi rongga mulut. Kriteria tersebut didiskusikan dengan focus group discussion bersama dengan peneliti, ketua komite PPI, dan 5 orang IPCN RSJRW. Untuk menghitung incidence rate digunakan rumus dengan membagi jumlah kasus yang terjadi dengan jumlah hari perawatan yang terpapar faktor risiko, dikalikan dengan konstanta 1000 (11). Denominator insiden plebitis adalah jumlah hari rawat pasien berisiko atau jumlah hari penggunaan infus yaitu 339 hari. Pada ISK digunakan denominator jumlah hari pemakaian kateter yaitu 48 hari sedangkan pada dekubitus adalah jumlah hari tirah baring 571 hari. Pada insiden lainnya digunakan denominator lama hari perawatan seluruh pasien karena memiliki risiko yang sama.

\section{HASIL}

Selama April 2016 didapatkan 834 pasien yang terdiri dari 373 pasien baru dan rawat ulang, 461 pasien yang telah dirawat sejak akhir Maret. Sebagian besar pasien adalah laki-laki ( $n=593,71 \%)$, rentang usia antara 25-44 tahun ( $n=640,76,74 \%)$, mempunyai pendidikan setingkat SD ( $n=384,46,04 \%)$. Infeksi nosokomial yang ditemukan pada periode penelitian sebanyak 30 insiden tunggal pada 30 pasien. Berdasarkan jumlahnya, infeksi nosokomial terbanyak adalah influenza-like ilness yang tergolong dalam infeksi saluran nafas $(n=8)$, gastroenteritis $(n=7)$, dan selulitis $(n=5)$. Insiden rate tertinggi adalah ISK $(20,83)$ dan phlebitis $(11,80)$ yang lebih tinggi dari target capaian angka infeksi nosokomial di RSJRW yaitu dibawah 5 permil per kejadian (Tabel 1)

Tabel 1. Jumlah dan Incidence Rate infeksi nosokomial RSJRW bulan April 2016

\begin{tabular}{clrr}
\hline \multicolumn{2}{c}{ Infeksi Nosokomial } & \multicolumn{2}{c}{ Kejadian } \\
\cline { 3 - 4 } 1 & Plebitis & $\mathbf{n}$ & \multicolumn{1}{c}{ IR } \\
2 & ISK & 4 & 11,80 \\
3 & Decubitus & 1 & 20,83 \\
4 & Influenza & 1 & 1,75 \\
5 & Selulitis & 8 & 0,56 \\
6 & Scabies & 5 & 0,35 \\
7 & Infeksi Jamur & 1 & 0,07 \\
8 & Infeksi herpes & 0 & 0,00 \\
9 & Kutu rambut & 2 & 0,14 \\
10 & Konjungtivitis & 0 & 0,00 \\
11 & Gastroenteritis & 0 & 0,00 \\
12 & Infeksi rongga mulut & 7 & 0,49 \\
JUMLAH KEJADIAN HAls & 1 & 0,07 \\
\hline
\end{tabular}

Dari 834 pasien yang dirawat selama bulan April 2016, yang menggunakan infus adalah sebanyak 65 pasien, yang menggunakan kateter 8 pasien, dan yang tirah baring adalah 90 pasien. Dari 30 insiden infeksi nosokomial yang 
Tabel 2. Faktor risiko infeksi nosokomial

\begin{tabular}{|c|c|c|c|c|c|c|}
\hline \multicolumn{2}{|c|}{ Hubungan } & \multirow{2}{*}{$\begin{array}{c}\text { Chi } \\
\text { Square }\end{array}$} & \multirow{2}{*}{$\begin{array}{l}\text { Odds } \\
\text { Ratio }\end{array}$} & \multicolumn{2}{|c|}{ Confident Interval } & \multirow{2}{*}{$\begin{array}{c}\text { Probabi } \\
\text { litas }\end{array}$} \\
\hline Faktor risiko & Infeksi & & & Lower & Upper & \\
\hline Jenis Kelamin & Infeksi Nosokomial & 0,018 & 0,946 & 0,427 & 2,097 & 0,892 \\
\hline Usia $<41$ tahun* & Infeksi Nosokomial & 9,995 & 0,324 & 0,156 & 0,674 & 0,002 \\
\hline Pendidikan & Infeksi Nosokomial & 7,198 & 1,177 & 0,518 & 2,674 & 0,126 \\
\hline Mobilitas Terganggu* & Decubitus & 8,288 & 16,578 & 1,488 & 184,65 & 0,004 \\
\hline Pemakaian Kateter* & ISK & 96,374 & 192,75 & 15,83 & 2346,93 & 0,000 \\
\hline Pemakaian Infus* & Plebitis & 47,797 & 62,419 & 7,18 & 542,64 & 0,000 \\
\hline Ruangan dengan Tindakan & Infeksi Nosokomial & 0,453 & 2,333 & 0,188 & 29,036 & 0,598 \\
\hline
\end{tabular}

Keterangan: Penetapan batas usia 41 didapat dari rata-rata usia 30 pasien yang mengalami infeksi nosocomial

ditemukan, 21 pasien adalah laki-laki (70\%), 15 pasien di rentang usia 25-44 tahun (50\%), 24 pasien tidak bekerja (80\%). Lama perawatan rata-rata yang mengalami insiden infeksi nosokomial 51 hari, dan ditemukan di 13 ruangan perawatan dari total 29 ruangan perawatan. Sesuai dengan faktor risiko nya, dari 30 insiden nosokomial tersebut, 1 pasien infeksi karena menggunakan kateter urin dari total 8 pasien dengan kateter, 4 pasien infeksi karena menggunakan infus dari total 65 pasien yang menggunakan infus, 1 pasien mengalami inkontinensia, dan 1 pasien infeksi karena mobilitas terganggu dari total 90 pasien yang tirah baring. Hasil menunjukkan faktorfaktor yang memiliki hubungan yang signifikan secara statistik terhadap terjadinya infeksi nosokomial adalah usia, mobilitas terganggu, pemakaian kateter, dan pemakaian infus (Tabel 2).

\section{DISKUSI}

\section{Gambaran Infeksi Nosokomial}

Dengan menggunakan kriteria baru, survei pada penelitian ini mengidentifikasi 30 kejadian infeksi, lebih tinggi dibandingkan kejadian yang ditemukan pada bulan Maret yang menggunakan kriteria Kemenkes. Perbedaan tersebut dapat disebabkan perbedaan jenis infeksi yang disurvei. Pada kriteria Mc Geer memasukkan infeksi kulit dan saluran pencernaan, sedangkan kriteria Kemenkes tidak. Sebaliknya, pada kriteria Kemenkes memasukkan infeksi aliran darah primer dan infeksi luka operasi yang tidak ada pada kriteria McGeer. Perbedaan tersebut disebabkan perbedaan intensitas tindakan, lama perawatan, yang mempengaruhi pola kuman dan infeksi.

Dari jenisnya, penelitian ini mengidentifikasi angka tertinggi adalah influenza. Hasil yang serupa juga ditemukan oleh Coady dan Magill yang mengidentifikasi bahwa ifluenza musiman atau infeksi saluran pernapasan paling banyak ditemukan pada pasien dewasa di fasilitas kesehatan jangka panjang $(12,13)$. Bila ditinjau dari tingkat insidennya, infeksi saluran kencing dan plebitis memiliki insiden rate tertinggi. Temuan serupa juga dilaporan oleh Smith dan Coady yang meneliti pada fasilitas kesehatan jangka panjang $(12,8)$. Meskipun memiliki pola sama, angka insiden yang ditemukan dirumah sakit pada penelitian ini jauh lebih tinggi dari kajian serupa di Amerika dan Kanada.

\section{Fakto Risiko Infeksi Nosokomial}

Penelitian mengidentifikasi usia, mobilitas terganggu, pemakaian kateter, dan pemakaian infus sebagai faktor risiko infeksi nosokomial sedangkan jenis kelamin dan pendidikan tidak merupakan faktor risiko. Hal ini dinyatakan juga dalam penelitian Salem (11) yang menyatakan tidak ada perbedaan yang signifikan antara jenis kelamin, usia, dan pendidikan terhadap kejadian infeksi nosokomial di fasilitas kesehatan jangka panjang. Coady dan Salem juga tidak menemukan hubungan yang signifikan antara usia dan jenis kelamin dengan kejadian infeksi nosokomial $(11,12)$. Sebaliknya Suka (14) dalam penelitiannya menyebutkan bahwa semakin dewasa atau semakin muda usia seseorang semakin berisiko untuk terkena infeksi nosokomial. Meskipun secara statistik memang tidak menggambarkan hubungan yang signifikan, tetapi ruangan dengan tindakan memiliki risiko 2,33 kali lebih besar untuk terkena infeksi nosokomial daripada ruangan perawatan tanpa tindakan.

Pasien dengan mobilitas terganggu memiliki risiko terkena infeksi nosokomial 16,57 kali lebih besar daripada pasien dengan mobilisasi baik. Dalam penelitian Agrawal dan Jaul dikatakan bahwa imobilitas merupakan faktor terjadinya ulkus tekan. Studi tersebut juga menyebutkan bahwa $70 \%$ kasus ulkus tekan dialami oleh pasien lanjut usia $(15,16)$.

Pemakaian kateter meningkatkan risiko terkena ISK sebesar 192,75 kali daripada pasien tanpa kateter. Penelitian Widodo (17) menggambarkan faktor risiko terbesar ISK (infeksi nosokomial) adalah penggunaan kateter. Widodo menggambarkan dari seluruh kejadian infeksi nosokomial di RS Dr.Cipto Mangunkusumo dari tahun 1999-2002 $(n=1317)$ terbanyak adalah karena penggunaan kateter (76\%). Markovic menemukan bahwa 94\% pasien dengan ISK menggunakan kateter urin (>>) (18).

Risiko terjadinya plebitis pada pasien dengan infus, lebih besar 62,41 kali daripada pasien yang tidak menggunakan infus. Penelitian Uslusoy (19) menggambarkan dari 568 pasien dengan menggunakan infus, 309 pasien mengalami plebitis (54,5\%). Penelitian Grune (20) menggambarkan incidence rate plebitis di sebuah rumah sakit di Jerman (periode Juni-Oktober 1998) adalah 27,1 kasus per 100 pasien, atau 104 kasus di setiap 1000 hari pemakaian infus. Lama hari pemakaian infus merupakan salah satu faktor risiko terjadinya plebitis. Kejadian plebitis meningkat secara signifikan setelah 24 jam pemakaian infus atau setelah 48 jam $(21,22)$.

Dari aspek lama hari perawatan, secara deskriptif ditemukan bahwa rata-rata hari perawatan dari ke-30 kejadian infeksi nosokomial adalah 51 hari. Nilai tengah hari perawatan pasien dengan infeksi nosokomial adalah 44 hari. Sehingga perlu diwaspadai pasien-pasien yang dirawat lebih dari 44 hari karena memiliki kecenderungan terjadinya infeksi nosokomial. Hal ini sebetulnya sudah dapat dikaitkan dengan ketentuan lama hari rawat di RSJRW yaitu \pm 42 hari. Perlu perhatian khusus apabila 
pasien dirawat melebihi hari rawat tersebut walaupun masa inkubasi masing-masing infeksi nosokomial dapat berbeda-beda mulai dari yang terendah 3 hari sampai dengan 20 hari.

Menurut Edwards di beberapa negara berkembang, surveilans infeksi nosokomial merupakan cara yang efektif untuk mengurangi dan mengendalikan insiden DA-HAI (device associated hospital acquired infections) di rumah sakit, dengan cara meningkatkan sistem keselamatan pasien dan mengurangi kejadian yang tidak diharapkan (23). Dalam penelitian Nimalie et al, diungkapkan bahwa kriteria McGeer dikembangkan dari definisi surveilans infeksi nosokomial CDC yang kemudian dikembangkan melalui konsensus dari pakar yaitu dokter, pakar geriatri, perawat infection control (24). Proses yang sama dilakukan peneliti ketika mengembangkan kriteria baru yang menggabungkan kriteria McGeer dan Kemenkes

\section{DAFTAR REFERENSI}

1. World Health Organization. Prevention of HospitalAcuired Infections. 2 edition. Malta: World Health Organization; 2002.

2. World Health Organization. Health Care-Associated Infections Fact Sheet. (Internet) 2015. http:// www.who.int/gpsc/country_work/gpsc_ccisc_fact_ sheet_en.pdf. [accessed on October 26, 2015].

3. Allegranzi B, Nejad BS, Combescure C, et al. Burden of Endemic Health-Care-Associated Infection in Developing Countries: Systematic Review and MetaAnalysis. Lancet. 2011; 377 (9761): 228-241.

4. Roberts RR, Scott RD, Hota B, et al. Costs Attributable to Healthcare-Acquired Associated Infections in Hospitalized Adults and a Comparison of Economics Methods. Medical Care. 2010; 48 (11): 1026-1035.

5. Burns K, Roche F, and Donlon S. Healthcareassociated Infections and Antimicrobial Use in Longterm Care Facilities: The Irish Experience with the HALT Surveys. The Journal of Hospital Infection. 2015; 89(4): 276-280.

6. Lee $S$, Rothbard $A B$, and Noll EL. Length of Inpatient Stay of Persons with Serious Mental IIIness: Effects of Hospital and Regional Characteristic. Psychiatric Services. 2012; 63(9): 889-895.

7. McGeer A, Campbell B, Emori TG, et al. Definitions of Infection for Surveillance in Long-term Care Facilities. American Journal of Infection Control. 1991; 19(1): 1-7.

8. Smith PW, Bennett G, Bradley S, et al. SHEA/APIC Guideline: Infection Prevention and Control in The Long-term Care Facility. American Journal of Infection Control. 2008; 36(7): 504-535.

9. Eilers E, Veldman-Ariesen MJ, Haenen A, and Van Banthem BH. Prevalence and Determinant Associated with Healthcare-Associated Infections in Long-term Care Facilities (HALT) in the Netherlands, May to June 2010. Euro Surveillance. 2012; 17(34): 1-6.

10. Donosepoetro IF, Rini NSH, dan Hakim L. Pencegahan dan Pengendalian Infeksi di RSJ Dr. serta pertimbangan profil infeksi di rumah sakit sesuai masukan dari provider kesehatan dan tim pengendalian infeksi di rumah sakit. Pemerintah perlu mengembangkan kriteria khusus infeksi nosokomial sesuai dengan karakteristik pelayanan, pasien, serta faktor lingkungan yang mempengaruhi. Kriteria yang dikembangkan pada proses penelitian ini dapat dijadikan model yang perlu dikaji dalam skala yang lebih luas sebagai dasar dalam mengembangkan kriteria baku infeksi nosokomial pada pelayanan kesehatan jiwa.

Dengan menggunakan kriteria baru pada penelitian ini dapat diidentifikasi 30 kejadian infeksi nosokomial selama bulan April 2016, dengan insiden tertinggi adalah ISK dan plebitis. Faktor risiko yang berpengaruh adalah usia, hambatan mobilitas, pemakaian kateter dan infus, sedangkan usia, jenis kelamin, dan ruangan dengan tindakan bukan merupakan faktor risiko.

Radjiman Wediodiningrat Lawang; Apa Kendala Pelaporannya? Jurnal Kedokteran Brawijaya. 2016; 29 (3): $269-272$.

11. Salem BK, Mhamdi ES, Letaief M, Bchir M, and Soltani MS. Epidemiological Profile of Healthcare Associated Infections in the Central East Area of Tunisia. Eastern Mediterranean Health Journal 2011; 17(6): 485-489.

12. Coady CF. Nosocomial Infections and Antibiotic Utilization in Long Term Care FAcilities: Traditional Versus Protective Care Setting. [Thesis]. Memorial University of Newfoundland, Newfoundland and Labrador. 1998.

13. Magill SS, Edwards JR, Bamberg W, et al. Multistate Point-Prevalence Survey of Health Care-Associated Infections. The New England Journal of Medicine. 2014; 370(13): 1198-1208.

14. Suka M, Yoshida K, and Takezawa J. Epidemiological Approach to Nosocomial Infection Surveillance Data: the Japanese Nosocomial Infection Surveillance System. Environment Health and Preventive Medicine. 2008; 13(1): 30-35.

15. Agrawal K and Chauhan N. Pressure Ulcers: Back to the Basics. Indian Journal of Plastic Surgery. 2012; 45(2): 244-254.

16. Jaul E. Assesment and Management of Pressure Ulcers in the Elderly: Current Strategies. Drugs \& Aging. 2010; 27(4): 311-325.

17. Widodo D and Astrawinata D. Surveillance of Nosocomial Infections in Dr. Cipto Mangunkusumo National General Hospital, Jakarta, 1999-2002. Medical Journal Indonesia. 2004; 13(2): 107-112.

18. Markovic-Denic L, Mijovic B, and Jankovic S. Risk Factors for Hospital-Acquired Urinary Tract Infection: A Case Control Study. International Urology and Nephrology. 2011; 43(2): 303-308.

19. Uslusoy E and Mete S. Predisposing Factors to Phlebitis in Patients with Peripheral Intravenous Catheters: A Descriptive Study. Journal of the American Academy of Nurse Practicioners. 2008; 20(4): 172-180.

20. Grune F, Schrappe M, Basten J, et.al. Phlebitis Rate and Time Kinetics of Short Peripheral Intravenous 
Catheters. Infection. 2004; 32(1): 30-32.

21. Karadag A and Gorgulu S. Effect of Two Different Short Peripheral Catether Materials on Phlebitis Development. Journal of Intravenous Nursing. 2000; 23(3): 158-166.

22. Maki DG and Ringer M. Risk Factors for Infusion Related Phlebitis with Small Peripheral Venous Catheters. Annals of Internal Medicine. 1991; 114(10): 845-854.
23. Edwards JR, Peterson KD, Mu Y, et al. National Healthcare Safety Network (NHSN) report: Data Summary for 2006 through 2008, issued December 2009. American Journal of Infection Control. 2009;37(10):783-805.

24. Stone MD, Ashraf MS, Calder J, et al. Surveillance Definitions of Infections in Long-Term Care Facilities: Revisiting the McGeer Criteria. Infection Control and Hospital Epidemiology. 2012; 33(10): 965-977. 